\title{
EFEITO DE FÁRMACOS ANESTÉSICOS NA FUNÇÃO RENAL DE CÃES
}

\author{
José Aloizio Gonçalves Neto' \\ Ronaldo Eugênio de Oliveira ${ }^{2}$ \\ Kamila Pandolfi ${ }^{3}$ \\ Rudison da Silva Florêncio 4 \\ Gabriela Porfirio-Passos 5 \\ Lenir Cardoso Porfirio 6
}

Resumo: Com o aumento na expectativa de vida dos animais como cães e gatos há necessidade de aperfeiçoar práticas anestésicas e fármacos para a obtenção do plano anestésico com mínimos efeitos colaterais. Os objetivos deste trabalho foram analisar parâmetros urinários antes e após os procedimentos anestésicos, a densidade urinaria, relação proteína:creatina urinária, atividade urinária das enzimas fosfatase alcalina e gama glutamiltransferase, em cães machos e fêmeas da raça labrador com aproximadamente $30 \mathrm{~kg}$ de peso e com uso de acepromazina na dose de 0,05 mg/Kg e meperidina $3 \mathrm{mg} / \mathrm{Kg}$ como medicação pré-anestésica, propofol na dose de $5 \mathrm{mg} / \mathrm{Kg}$ para indução e a manutenção anestésica foi realizada com isofluorano em 1,5 CAM. Concluiu-se, este protocolo anestésico em procedimentos cirúrgicos não ocasionaram alterações nos parâmetros renais que indicasse lesão. Todos os valores da atividade urinária das enzimas gGT, FA, da DU e da UPC se mantiveram dentro dos parâmetros fisiológicos de cães saudáveis e não houve relação negativa pelo uso dos anestésicos nas doses utilizadas.

Palavras-chave: Anestesia; Cirurgia; Cães.

\footnotetext{
${ }^{1}$ Medicina Veterinária /Universidade Federal do Espirito Santo Brasil. E-mail: aloiziogon@gmail.com.

${ }^{1}$ Medicina Veterinária /Universidade Federal do Espirito Santo Brasil. E-mail: ronaldo.oliveira@ufes.com.br.

${ }^{1}$ Medicina Veterinária /Universidade Federal do Espirito Santo Brasil. E-mail: kamilapandolfi@yahoo.com.br.

${ }^{1}$ Medicina Veterinária /Universidade Federal do Espirito Santo Brasil. E-mail: rudi.florencio@gmail.com.

${ }^{2}$ Medicina Veterinária /Universidade Federal da Bahia, Brasil. E-mail: gporfiriopassos@gmail.com.

${ }^{1}$ Medicina Veterinária /Universidade Federal do Espirito Santo Brasil. E-mail: Ienircp52@gmail.com.
} 